\title{
Consolidation of Al-nanoSiC Composites by Spark Plasma Sintering
}

\author{
Ridvan Yamaoglu and Eugene A. Olevsky
}

\begin{abstract}
In the current study, nano-sized SiC particulate aluminium alloy powders ranging in size from 150 to $250 \mu \mathrm{m}$ produced by a plasma rotating electrode process were synthesized by spark plasma sintering (SPS). The relationship between sintering parameters as a function of temperature, holding time, pressure and heating rate was investigated. The microstructure of the sintered composite compacts was also assessed. The density and microstructure were influenced by the eutectic phase in the aluminum alloy. Maximum relative density $(100 \%)$ was obtained at $450{ }^{\circ} \mathrm{C}$, under $50 \mathrm{MPa}$ pressure, with 5 min soaking time and $100{ }^{\circ} \mathrm{C} / \mathrm{min}$ heating rate.
\end{abstract} SPS.

Index Terms-Aluminium, eutectic melting, nano composite,

\section{INTRODUCTION}

Metal matrix composites are attractive in many applications thanks to their unique properties [1]. A number of studies have been conducted on the effect of fine particles [2]. However, the effect of nanosize particulates is still under consideration. Metal matrix nanocomposites are composed of a soft metal matrix and hard reinforcements which are embedded in a ductile metal or alloy matrix. Nano particulate metal matrix composites have received much attention because of their enhanced properties as a result of the size and strength of the nanosize reinforcements compared with typical metal matrix composites [3]. Gupta and colleagues showed that the addition of 0.66 volume percent of nano-sized alumina led to an improvement in mechanical properties unmatched even by AZ91/SiC composites with a much higher volume fraction of micronsized SiC particles [4]. Among the metal matrixes, aluminum and its alloys have widespread application thanks to their superior properties [5]. Especially in powder metallurgy, the use of aluminum alloys is motivated by the formation of eutectic phases with a low melting point, and this permits liquid phase sintering resulting in high performance alloys [6]. Most researches on the sintering of aluminum alloys have focused on blended powders in which liquid phase sintering begins with a mixture of two or more powders of different composition [7]. In the current study, a

Manuscript received January 28, 2015; revised July 23, 2015. This Study was supported by Tubitak (The Scientific and Technological Research Council of Turkey). This material is based on work supported by the US Department of Energy, Materials Sciences Division, under Award No.DE-SC0008581, through the Powder Technology laboratory at the San Diego State University.

Ridvan Yamaoglu is with the Department of Metallurgical and Materails Engineering, Kocaeli University, Umuttepe Campus, Kocaeli 41380, Turkey (e-mail: ryamanoglu@ gmail.com).

Eugene A. Olevsky is with the Department of Mechanical Engineering, San Diego State University, San Diego, California 92182-1323, USA (email: eolevsky@mail.sdsu.edu) pre-alloyed aluminum alloy consisting of eutectic phases and particulated with nano $\mathrm{SiC}$, preferred for many applications in the aerospace and automobile industries in applications such as heat sinks, drive shafts, brake rotors, aircraft fins and different engine components [8], was produced by a plasma rotating electrode process (PREP) and consolidated by spark plasma sintering (SPS). Spark plasma sintering is a novel sintering method for producing components with high density at relatively low process temperatures and short soak times compared with conventional sintering techniques [9]-[11]. The present study presents detailed information on the spark plasma sintering of Al-nanoSiC composites.

\section{EXPERIMENTAL}

An $\mathrm{Al}-\mathrm{Cu}-\mathrm{Mg}$ alloy $\left({ }_{0.42} \mathrm{Si}_{-0.52} \mathrm{Fe}-{ }_{4.01} \mathrm{Cu}-0.43 \mathrm{Mn}-{ }_{1.36} \mathrm{Mg}-0.13\right.$ $\mathrm{Cr}_{0.03} \mathrm{Zn}_{0.01} \mathrm{Ti}_{-}$remainder $\mathrm{Al} / \mathrm{wt}-\%$ ) reinforced with $4 \mathrm{wt} \% \mathrm{SiC}$ particles with $650 \mathrm{~nm}$ average particle size was used as starting material. The composite alloy was atomized by a plasma rotating electrode process under argon atmosphere with a pressure of $1.3 \mathrm{~atm}$. The rotation speeds of the anode bars were 3500, 800 and $12000 \mathrm{rpm}$, to produce powders with different particle size distribution. The powders were investigated with optical and scanning electron microscopy. Loose starting powder with a particle size range of 150 to $250 \mu \mathrm{m}$ was densified with a Dr. Sinter Lab 515S SPS machine (SPS Syntex, Co., Japan) and poured directly into a graphite die with a $15.4 \mathrm{~mm}$ inner diameter lined with graphite paper for lubrication and ease of compact release. A schematic image of the SPS process is shown in Fig. 1.

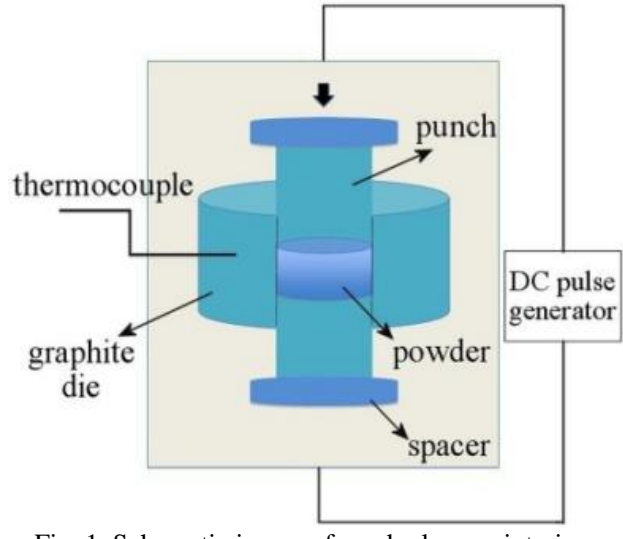

Fig. 1. Schematic image of spark plasma sintering.

The powder was sintered at 400 and $450{ }^{\circ} \mathrm{C}$ with different heating rates from 50 to $100{ }^{\circ} \mathrm{C} / \mathrm{min}$, followed by 5 or 10 min holding time under 25 and $50 \mathrm{MPa}$ pressure. At the end of the holding time, the applied current was switched off and the specimens were kept inside the chamber and cooled to 
room temperature. The densities of the sintered compacts were measured with the Archimedes method, and then the relative densities of the compacts were determined with reference to the theoretical density calculated by a helium pycnometer (Micromeritics AccuPyc 1330) of $2,78 \mathrm{gcm}^{-3}$. The specimens were metallographically prepared in the usual manner, thoroughly cleaned with alcohol and then dried with a hot air blower. Microstructural characterization of the sintered composites was carried out with a Keyence VHX-600 digital HD CCD microscope.

\section{RESULTS}

Optical micrographs of the atomized anode bar are shown in Fig. 2. The microstructure of the cast bar shows a coarse dendritic pattern with $\mathrm{SiC}$ particles distributed mainly in the interdendritic area. The secondary dendrite arm spacing (SDAS) of the cast bar was measured as $54 \mu \mathrm{m}$.
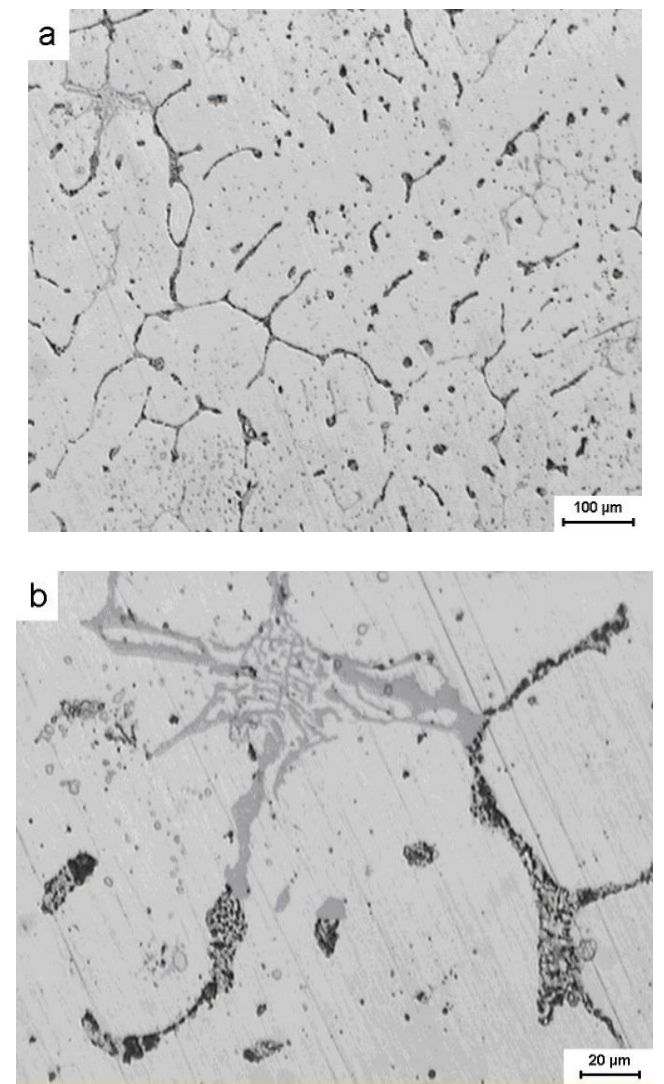

Fig. 2. Optical images of the atomized bar, a) low, b) high magnification.

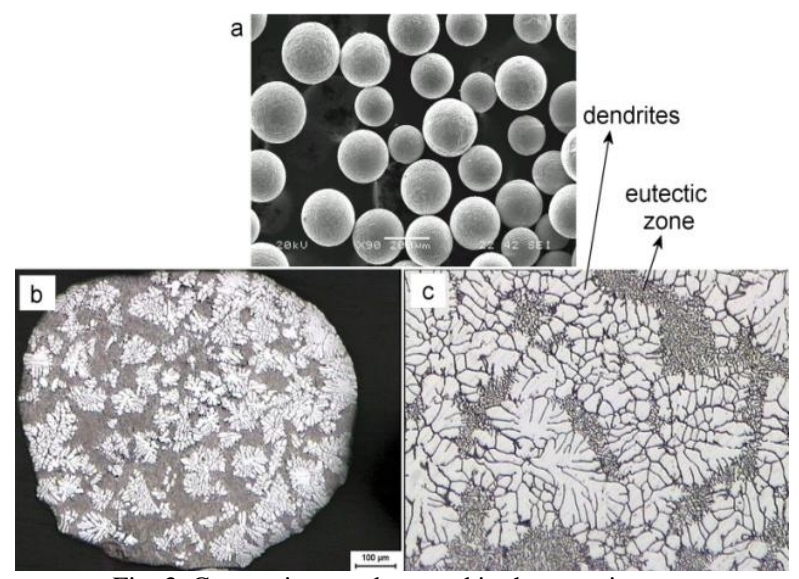

Fig. 3. Composite powders used in the experiments.
The powders used in the current study prior to sintering are given in Fig. 3. The production of pre-alloyed nanoSiC/Al composite powder by plasma rotating electrode process and eutectic formation are discussed elsewhere [1]. The powders produced by atomization are primarily of spherical shape, as seen in Fig. 3a. The optical micrographs of the solidified composite particles showed that each particle consists of dendritic and fine eutectic phases (Fig. $3 \mathrm{~b}$ and Fig. c).

Powders produced at different rotation speeds were sieved in $100 \mathrm{~g}$ quantities. The relationship of rotational speed and particle size can be seen in Fig. 4. Increased rotational speed produced finer sized particulate powders.
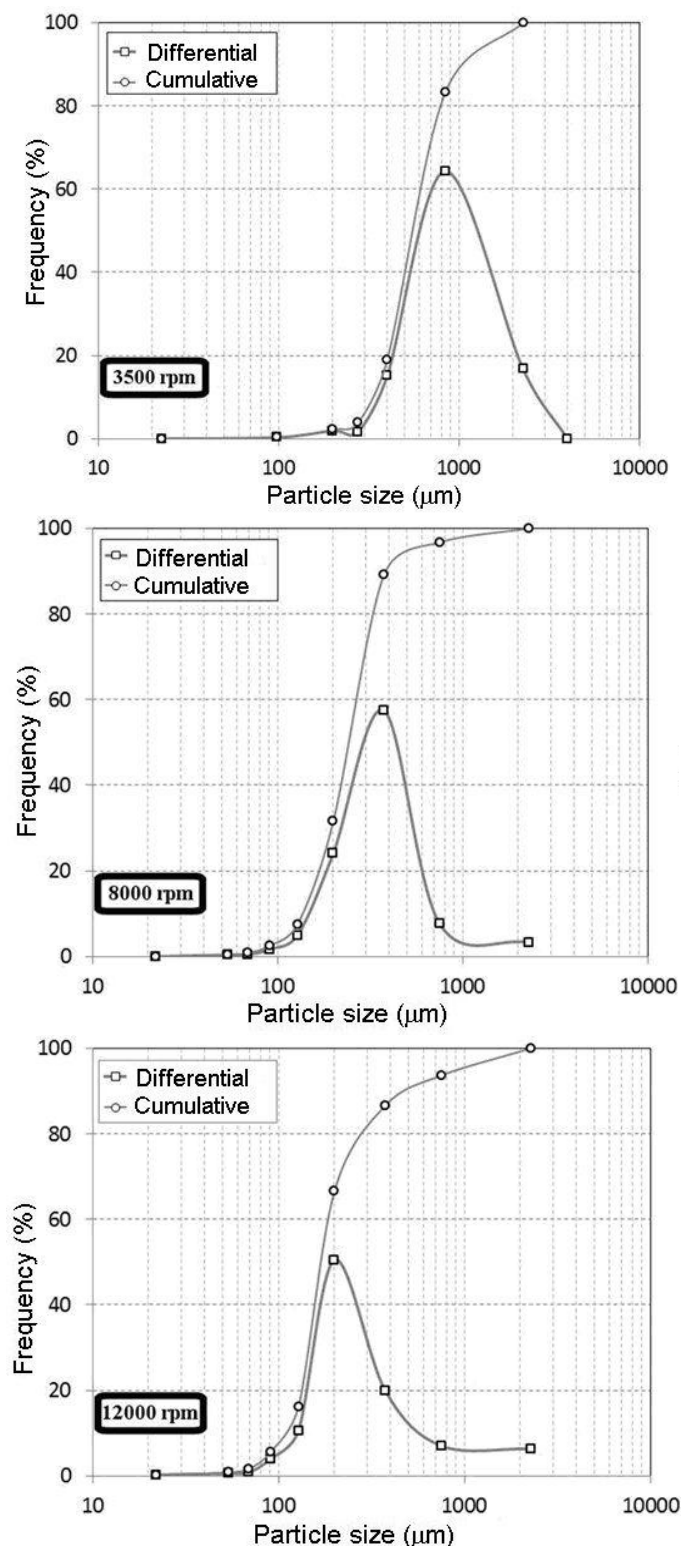

Fig. 4. Size distribution of powders depending on rotational speed.

The secondary dendrite arm spacing measurements were also carried out for the produced particles. Smaller particles showed finer SDAS. The particles with the size of 47, 250 and $450 \mu \mathrm{m}$ showed $0.85,4.16$ and $9.97 \mu \mathrm{m}$ SDAS values respectively due to higher cooling rates compared to conventional cast sample.

The spark plasma sintering parameters used for the sintering of nano SiC particulate aluminum alloy are given 
in Table I. Four different sintering regimes were selected to determine the effect of the selected parameters on the consolidation of the composite powders. Low sintering temperatures were selected because of the spark effect of SPS and the presence of eutectic phases in the alloy. In the first regime, only sintering temperature was varied and the same holding time, pressure and heating rate were maintained. In the second regime, the heating rate was increased from 50 to $100{ }^{\circ} \mathrm{C} / \mathrm{min}$. In the third regime, pressure was altered from 25 to $50 \mathrm{MPa}$ and in the final stage both pressure and heating rate were changed as in Table I.

TABLE I: SINTERING PARAMETERS USED FOR SPS OF NANO PARTICULATE ALUMINIUM ALLOY

\begin{tabular}{cccccc}
\hline \hline $\begin{array}{c}\text { Sample } \\
\text { Code }\end{array}$ & $\begin{array}{c}\text { Temperature } \\
\left({ }^{\circ} \mathrm{C}\right)\end{array}$ & $\begin{array}{c}\text { Pressure } \\
(\mathrm{MPa})\end{array}$ & $\begin{array}{c}\text { Time } \\
(\mathrm{min})\end{array}$ & $\begin{array}{c}\text { Heating } \\
\text { Rate } \\
\left({ }^{\circ} \mathrm{C} / \mathrm{min}\right)\end{array}$ & $\begin{array}{c}\text { Relative } \\
\text { Density } \\
(\%)\end{array}$ \\
\hline A1 & 400 & 25 & 5 & 50 & 93,8 \\
A2 & 450 & 25 & 5 & 50 & 99,2 \\
A3 & 400 & 25 & 5 & 100 & 93,6 \\
A4 & 450 & 25 & 5 & 100 & 97,6 \\
A5 & 400 & 50 & 5 & 50 & 98,5 \\
A6 & 450 & 50 & 5 & 50 & 99,8 \\
A7 & 400 & 50 & 5 & 100 & 99,3 \\
A8 & 450 & 50 & 5 & 100 & 100,0 \\
\hline
\end{tabular}
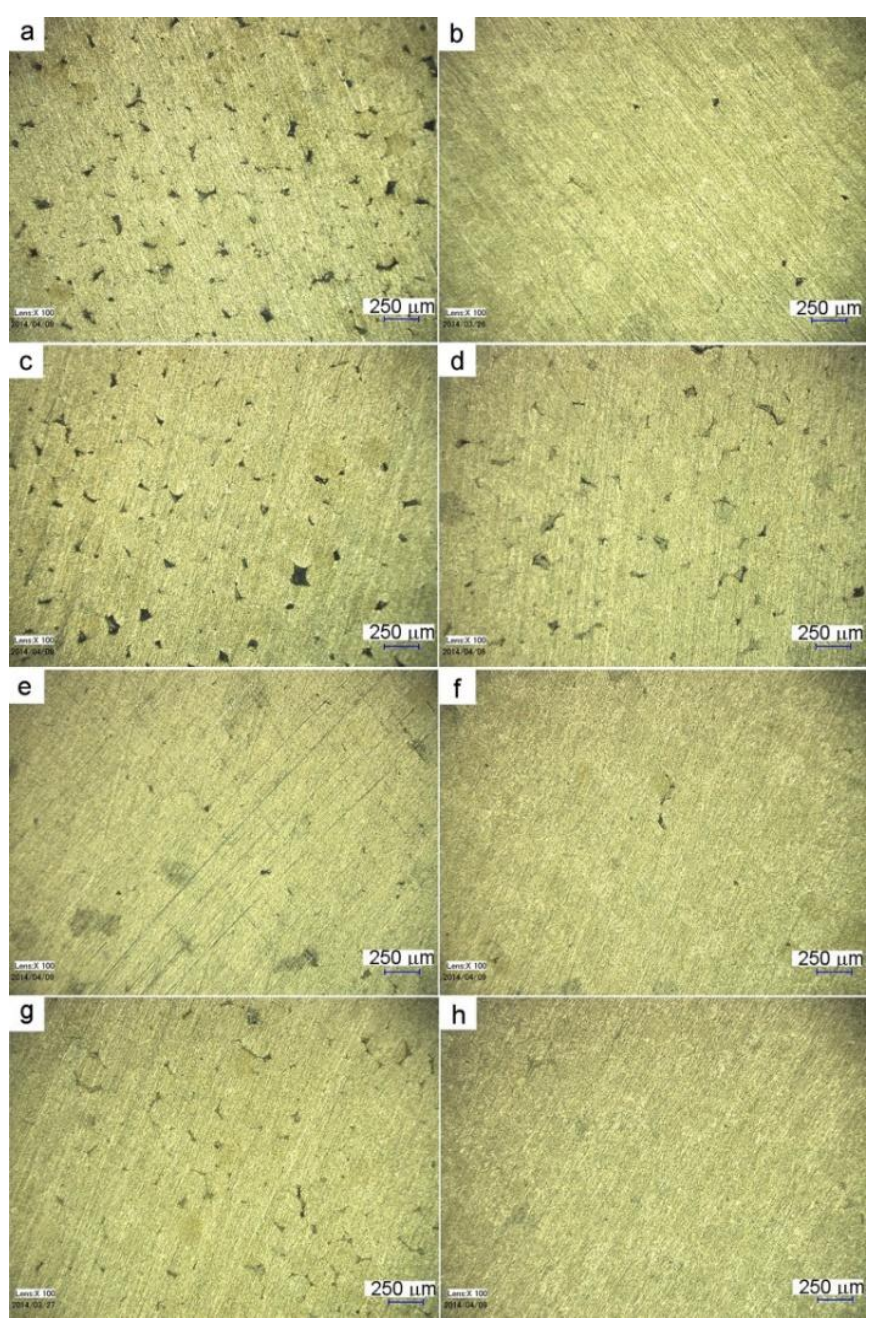

Fig. 5. Optical micrographs of SPS sintered composite compacts, a) A1, b) A2, c) A3, d) A4, e) A5, f) A6, g) A7 and h) A8.

In all sintering regimes, temperature played a strong role in the densification of the composite material. The relative densities of the compacts sintered at 400 and $450{ }^{\circ} \mathrm{C}$ with a holding time of $5 \mathrm{~min}$ and a heating rate of $50{ }^{\circ} \mathrm{C} / \mathrm{min}$ under $25 \mathrm{MPa}$ pressure were 93.8 and $99.2 \%$ respectively. At this point, heating rate was increased from 50 to $100{ }^{\circ} \mathrm{C} / \mathrm{min}$ and the other parameters were kept constant. It is clear that the density decreased with increasing heating rate. The density decreased from 93.8 to $93.6 \%$ and from 99.2 to $97.6 \%$ for sintering temperatures of 400 and $450{ }^{\circ} \mathrm{C}$ respectively. However, when we increased the pressure with the heating rate, the density increased extensively as shown in Table I. Besides heating rate, pressure also has an effect on densification. Density increased about 5\% for sintering temperature of $400{ }^{\circ} \mathrm{C}$ and $0.6 \%$ for sintering temperature of $450{ }^{\circ} \mathrm{C}$. Maximum relative density was obtained at $450{ }^{\circ} \mathrm{C}$, with 5 min soaking time and $100{ }^{\circ} \mathrm{C} / \mathrm{min}$ heating rate under $50 \mathrm{MPa}$ pressure. Fig. 5 shows the optical micrographs of the spark plasma sintered compacts. As can be seen from the figures, the microstructures are in good harmony with the density results.

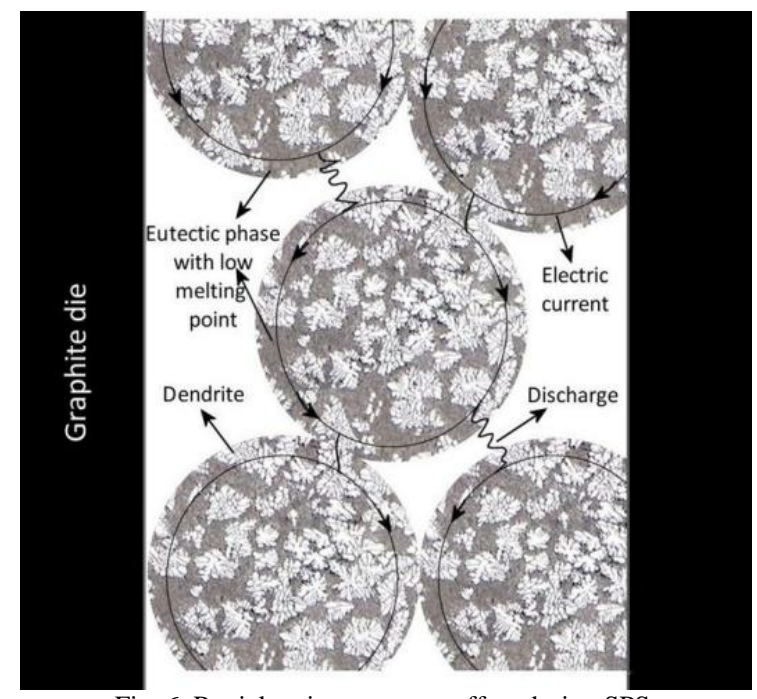

Fig. 6. Particle microstructure effect during SPS.

\section{CONCLUSION}

In the current study, sintering parameters and eutectic phase effect on densification were studied. In the light of the experimental results, the following conclusions are drawn. The eutectic phase consisting of $\mathrm{Al}_{2} \mathrm{Cu}$ and $\mathrm{Mg}_{2} \mathrm{Si}$ can be expected to affect the sintering of the composite because of the metals' lower melting point (1). Joule effect and electric discharge owed to a high heating rate were generated at the particle boundaries during spark sintering of the composite particles, local temperature of the contact point increased and eutectic melting occurred along the particle boundaries resulting in high relative density. Fig. 6 shows a schematic model of the eutectic phase effect during SPS. Having a liquid phase in the material during the process activates the sintering. At higher temperature $\left(500{ }^{\circ} \mathrm{C}\right)$, a separation was observed between liquid and solid because of pressure applied during the SPS process. Almost all liquid was separated from the composite material, leaving large pores behind. For this reason, the temperature was decreased to 400 and $450{ }^{\circ} \mathrm{C}$ for the current study. An increase in the amount of the liquid phase by means of an increase of 
sintering temperature caused an increase in densification at those temperatures.

The density of the composite material increased with increasing sintering temperature and pressure. High heating rate caused a decrease in the density. However, high heating rate with increasing pressure resulted in high density. Maximum (100\%) relative density was obtained at $450{ }^{\circ} \mathrm{C}$ for $5 \mathrm{~min}$ holding time with $100{ }^{\circ} \mathrm{C} / \mathrm{min}$ heating rate under $50 \mathrm{MPa}$ pressure. High heating rate especially at high temperatures promoted eutectic melting in the composite, resulting in high relative density.

\section{REFERENCES}

[1] R. Yamanoglu, M. Zeren, and R. M. German, "Solidification characteristics of atomized AlCu4Mg1-Sic composite powders," $J$ Min Metall SecT B-Metall, vol. 48, no. 1, pp. 73-79, 2012.

[2] J. Lan, Y. Yang, and X. Li, "Microstructure and microhardness of SiC nanoparticles reinforced magnesium composites fabricated by ultrasonic method," Mat Sci Eng A-Struct, vol. 386, pp. 284-290, 2004.

[3] N. Saheb, Z. Iqbal, A. Khalil, A. S. Hakeem, N. A. Aqeeli, T. Laoui, A. Al-Qutub, and R. Kirchner, "Spark plasma sintering of metals and metal matrix nanocomposites: A review," J Nanomater, pp. 1-13, 2012.

[4] S. F. Hassan and M. Gupta, "Development of high performance magnesium nano-composites using nano- $\mathrm{Al}_{2} \mathrm{O}_{3}$ as reinforcement," Mat Sci Eng A-Struct, vol. 392, pp. 163-168, 2005.

[5] G. L. You, N. J. Ho, and P. W. Kao, "Aluminum based in situ nanocomposite produced from $\mathrm{Al}-\mathrm{Mg}-\mathrm{CuO}$ powder mixture by using friction stir processing," Mater Lett, vol. 100, pp. 219-222, 2013.

[6] L. P. Barbosa, E. P. R. Lima, D. Rodrigues, and F. A. Filho, "Effect of compacting pressure on liquid phase sintering of ASTM 2124 alloy," Mater Sci Forum, pp. 623-628, 2010.

[7] H. Momeni, H. Razavi, and S. G. Shabestari, "Effect of supersolidus liquid phase sintering on the microstructure and densification of the Al-Cu-Mg pre-alloyed powder," International Journal of Multidisciplinary Sciences and Engineering, vol. 8, pp. 10-17, 2011.

[8] Y. S. Lee, B. H. Yeon, S. K. Hyun, and K. J. Kang, "A new fabrication method to improve metal matrix composite dispersibility," Mater Lett, vol. 89, pp. 279-282, 2012.

[9] R. Yamanoglu, W. Bradbury, E. A. Olevsky, and R. M. German, "Sintering and microstructure characteristics of 42CrMo4 steel processed by spark plasma sintering," Met. Mater. Int, vol. 19, no. 5 , pp. 1029-1034, 2013.
[10] R. Yamanoglu, W. Bradbury, E. Karakulak, E. A. Olevsky, and R. M German, "Characterisation of nickel alloy powders processed by spark plasma sintering," Powder Metall, 2014.

[11] A. Teber, F. Schoenstein, F. Tetard, M. Abdellaoui, and N. Jounini, "Effect of SPS process sintering on the microstructure and mechanical properties of nanocrystalline TiC for tools application," J Refract Met, vol. 30, pp. 64-70, 2012.

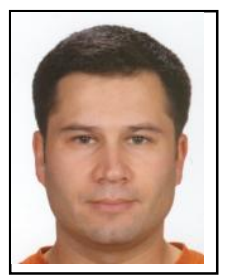

Ridvan Yamanoglu was born in Bilecik and he graduated from the Kocaeli University, Izmit, Department of Metallurgical and Materials Engineering in 2002. He received his M.Sc. degree in 2005 and his $\mathrm{PhD}$ in 2011 from the Kocael University. $\mathrm{He}$ has been working at the same university since 2002. He was awarded by Turkish Scientific Council during his $\mathrm{PhD}$. He studied his $\mathrm{PhD}$ at San Diego State University with Randall $\mathrm{M}$. German and Eugene A. Olevsky. He also studied at the same university with Dr. Eugene Olevsky in 2014. Dr. Yamanoglu published several journal and conference papers and attended 4 international course on powder metallurgy.

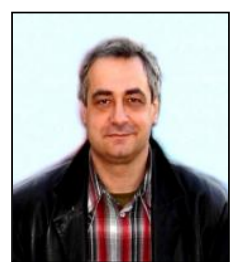

Eugene Olevsky is a distinguished professor of mechanical engineering at San Diego State University (SDSU), California, USA. Prof. Olevsky is the director of the SDSU Powder Technology Laboratory currently conducting research on the field-assisted and conventional sintering of functionally-structured materials for various applications. Prof. Olevsky is the author of more than 350 scientific papers, and more than 150 invited talks and presentations. During his academic career, Dr. Olevsky has advised more than 50 graduate and post-doctoral students. He is a fellow of the American Ceramic Society, a fellow of the American Society of Mechanical Engineers, Humboldt Fellow, and a recipient of numerous domestic and international professional awards and recognitions. Prof Olevsky is a recipient of the "Mega-Grant" Leading Scientist Award from the Ministry of Science and Education of Russian Federation. 


\section{Mechanical Control Engineering and Robotics}


